\title{
Influence of Chloride Ions on Corrosion Behavior of Steel Bars in a Simulated Concrete Pore Solution
}

\author{
Hongwei Wu ${ }^{1}$, Keyu Pan ${ }^{1}$, Yi Dai ${ }^{1}$,Hesong $\mathrm{Jin}^{1}$, Fuhai Li ${ }^{1,2, *}$ \\ ${ }^{1}$ School of Civil Engineering, Southwest Jiaotong University, Chengdu 610031, China \\ ${ }^{2}$ Key Laboratory of High-Speed Railway Engineering, Ministry of Education, Southwest Jiaotong \\ University, Chengdu 610031, China \\ *E-mail: Lifuhai2007@ home.swjtu.edu.cn
}

doi: $10.20964 / 2019.06 .52$

Received: 1 February 2019 / Accepted: 28 March 2019 / Published: 10 May 2019

\begin{abstract}
The performance of steel bars deteriorates under chloride corrosion. It is thus essential to study the corrosion mechanism of different steel bars to better understand the corrosion of steel bars in concrete structures. In this study, electrochemical techniques and scanning electron microscopy are used to study different steel bars in a simulated concrete pore solution after different numbers of days. The findings suggest that each sample's free corrosion potential, impedance arc radius, and dispersion parameter decrease as the corrosion rate increases. When corrosion begins, the passive film remains unchanged, and one time constant is observed. Then, when the passive film is destroyed, two time constants appear. The pits exhibit a stepped structure with a discrete diameter and penetrate to the bottom of the passive layer. As the corrosion proceeds, the pits begin to overlap. The steel bar's fractal dimension first increases and then decreases. These results describe both the average characteristics and the details of the corrosion, providing theoretical guidance for choosing steel bars and monitoring corrosion.
\end{abstract}

Keywords: Steel bar corrosion; Polarization measurement; EIS; SEM; Fractal dimension;

\section{$\underline{\text { FULL TEXT }}$}

(C) 2019 The Authors. Published by ESG (www.electrochemsci.org). This article is an open access article distributed under the terms and conditions of the Creative Commons Attribution license (http://creativecommons.org/licenses/by/4.0/). 